\title{
Antibacterial Effects of Water Extracts of Various Broadleaf Wild Leeks (Allium ampeloprasum)
}

\author{
Armin Tavakkoli ${ }^{1}$, Barat Oboudi ${ }^{2}$ and Alireza Tavakkoli ${ }^{3}$ \\ 1. Science Department, Leman Manhattan Preparatory School, New York 10004, USA \\ 2. Pathobiology Department, Shahriar Hospital Laboratories, Shiraz 71356, Iran \\ 3. Food Testing Department, TIECO Laboratories, Shiraz 71446, Iran
}

\begin{abstract}
There are numerous reports regarding the antimicrobial effects of herbal extracts on bacteria and fungi. We have prepared water extracts of Wild Leek (A. ampeloprasum var. porrum), Kurrat (A. ampeloprasum var. kurrat) and Elephant Garlic (A. ampeloprasum var. ampeloprasum) by rotary vacuum distillation. As a result, the extraction was carried out in $40{ }^{\circ} \mathrm{C}$ thus omitting any risk of loss of anti-bacterial activity due to high temperatures reported in prior similar studies [1]. The five bacteria Bacillus subtilis, Pseudomonas aeruginosa, Escherichia coli, Enterococcus faecalis, and Staphylococcus aureus were tested against the extracts. While some extent of inhibition was observed when the bacteria were cultured in presence of the leek and kurrat extracts, elephant garlic was determined to possess an extreme inhibitory quality against all the aforementioned bacteria, completely inhibiting the growth of the bacteria after $24 \mathrm{hrs}$ of culture in exposure to the extract. We propose that elephant garlic extract could be an effective alternative to chemical antibiotic treatments and disinfectants in hospital and other settings in which infections are common.
\end{abstract}

Key words: Elephant garlic, kurrat, leek, Bacillus subtilis, Pseudomonas aeruginosa, Escherichia coli, Staphylococcus aureus, Enterococcus faecalis, water extracts, inhibition.

\section{Introduction}

According to CDC, 722,000 hospital infections occurred in 2011 which lead to death of more than 75,000 patients [2]. Uses of chemical antibiotics have led to development of resistant bacteria that account for majority of hospital infections [1, 3, 4]. Consequently, there is an urgent need to identify natural sources that are able to prove effective on these bacteria, are not costly and are readily available to use. Members of the Allium family and specifically Allium cepa (the common onion) have long been thought of to exhibit anti-bacterial qualities [5, 6]. While numerous studies have been published investigating this claim, we were not able to identify any that concentrated mainly on the members of the broadleaf wild leek (Allium ampeloprasum) family. [5-15,]

Broadleaf wild leeks (commonly referred to as leeks)

Corresponding author: Armin Tavakkoli, I.B. Diploma candidate, research fields: microbiology and antimicrobial agents. E-mail: art2006@med.cornell.edu. are thought to have been first cultivated in Greece and Mediterranean regions thus accounting for major parts of their diet. This family consists of three members that are known as: Wild Leek (A. ampeloprasum var. porrum), Kurrat (A. ampeloprasum var. kurrat) and Elephant Garlic (A. ampeloprasum var. ampeloprasum).

The objective of this study was to examine the antibacterial effect of extracts of broadleaf wild leek family and evaluate the possibility of using them as effective disinfectants and antibacterial agents to avoid infections in settings such as hospitals. Possible uses of these natural disinfectant agents could omit side effects such as those seen in chemical antibiotics and be effective in prohibiting development of resistant bacteria.

\section{Materials and Methods}

\subsection{Broadleaf Wild Leeks}

Three types of broadleaf wild leeks Wild Leek ( $A$. ampeloprasum var. porrum), Kurrat (A. ampeloprasum 
var. kurrat) and Elephant Garlic (A. ampeloprasum var. ampeloprasum) were chosen for this investigation. Leek and kurrat, originally cultivated in Fars providence, were obtained from local gardens where the origin and identity of the plants were confirmed. Elephant garlic is primarily cultivated in Hormozgan region where they were obtained. Samples were shipped and stored in $3^{\circ} \mathrm{C}$ prior extraction.

\subsection{Microbial Strains}

The microorganism were obtained from the Shiraz Shahriar hospital's laboratory and isolated on pure culture on SBA (sheep blood agar) (Merck, Germany) and Mueller Hinton agar medium (Merck, Germany). The bacteria were selected because they are frequently found in relation to infections present in hospital settings, bodily infections and food poisonings. [4, 8, 12] Five species of bacteria, Bacillus subtilis, Pseudomonas aeruginosa, Escherichia coli, Enterococcus faecalis, and Staphylococcus aureus were used in this study.

\subsection{Water Extraction}

The samples were extracted using rotary vacuum distillation, commonly used in extraction of heat sensitive materials. This method omitted any risk of loss of antibacterial activity due to heat or PH reported in previous studies. $[1,13]$ Samples were rinsed with sterile distilled water and the bulb part of the samples was chopped down in small pieces. 500 grams of each sample were homogenized in 250 milliliters of distilled water using a domestic blender (KHH326WH, Kenwood, Japan). The homogenates were prepared according to a prior study [7]. Homogenates were left overnight in $3^{\circ} \mathrm{C}$ to allow proper diffusion of plant's chemical substances. Homogenates were then heated at $40{ }^{\circ} \mathrm{C}$ and distilled using a rotary vacuum distillation unit thus obtaining the crude water extract for experimentation.

\subsection{Inoculum Preparation}

For each organism, a bacterial suspension matching the $0.5 \mathrm{McFarland}$ standard turbidity was made in sterile distilled water to reach a microbial concentration of $\approx 1.5 \times 10^{8}$ colony forming units using the direct colony suspension method. A 1/100 dilution of bacterial inoculum was prepared and sub cultured using a $0.001 \mathrm{cc}$ bacteriological loop in order to have a control growth.

\subsection{Antibacterial Activity Test}

The antibacterial activity test was performed in two steps in order to insure the validity of the results.

\subsubsection{Step One}

In order to study the antibacterial effect of the mentioned herbal extracts, a macro tube dilution method was performed. Tubes containing $1 \mathrm{~mL} / \mathrm{g}$ TSB (tryptic soy broth) (Merck, Germany) were prepared. $100 \ell$ of the inoculum was then added to each tube and thoroughly mixed. One milliliter of each extract was then added to each tube of different bacteria. The inoculated tubes (extract + Bacteria) were incubated for $24 \mathrm{hrs}$ at $37{ }^{\circ} \mathrm{C}$. After the incubation time was completed, tubes were inspected macroscopically and growth status was determined.

\subsubsection{Step Two}

Using a $0.001 \mathrm{cc}$ loop, a sample of the incubated tubes was transferred to a MHA (Mueller Hinton Agar) (Merck, Germany) plate and incubated for $24 \mathrm{hrs}$ at 37 ${ }^{\circ} \mathrm{C}$. After the incubation time was completed, plates were inspected for any growth and were given an inhibition factor of $0,1,2,3$ or 4 each indicating no inhibition, less than a $25 \%$ reduction in CFU intensity, less than a 50\% reduction in CFU intensity, less than a $75 \%$ reduction in CFU intensity and complete inhibition respectively.

\subsubsection{Data Re-validation}

In order to validate the data in regard to the most effective extract, the marked extract was tested again against all the bacteria using the well-plate diffusion method. $6 \mathrm{~mm}$ wells were made in a Muller Hinton agar plate (Germany, Merck) and were filled with the crude extract. Bacterial inoculum prepared to match the 
0.5 McFarland turbidity was then spread over the plate using a sterile applicator. After $24 \mathrm{hrs}$ of incubation the plates were inspected for zones of inhibition.

\section{Results and Discussion}

\subsection{Antibacterial Activity of Water Extracts}

Kurrat and leek extracts showed different inhibition levels against the five bacteria. Elephant garlic however was found to completely inhibit the growth of all five bacteria as shown in Table 1 and Fig. 1.

In comparison, kurrat and leek extracts proved to have no inhibitory ability against $P$. aeruginosa, Enterococcus faecalis and E. coli. Leek was found to have a better inhibitory strength in comparison to kurrat against B. subtilis. Kurrat showed a higher inhibition in comparison to leek when put against $S$. aureus.

In data re-validation process, the elephant garlic extracts in undiluted concentrations showed a $30 \mathrm{~mm}$ zone of inhibition and a $17 \mathrm{~mm}$ zone of inhibition when the concentration was reduced to $50 \%$.

\subsection{Discussion}

The antibacterial effects of major herbal extracts have been researched and analyzed by extensive group of researchers worldwide. Researchers worldwide have reported numerous methods to obtain extracts of different herbs. However in our method the absence of any disinfectant agents (such as those in methanoic extraction) further assures us that the inhibitory qualities are solely the properties of the herbs and have not been affected by any other factors. Our results have shown that some of the mentioned herbs could potentially replace the chemically engineered antibiotics. Previous researches suggest that herbal alternatives may prove effective in omitting unforeseen side effects that are known to occur as a result of antibiotic consumption [6,9].

However, despite the abilities that herbal plants have

Table 1 Results of antibacterial activity.

\begin{tabular}{|c|c|c|c|c|c|}
\hline Extract/Bacteria & S. aureus & E. coli & B. Subtilis & E. faecalis & P. aeruginosa \\
\hline Leek & $1(<25 \% \downarrow$ intensity $)$ & 0 (No. inhibition) & $2(<50 \% \downarrow$ intensity $)$ & 0 (No. inhibition) & 0 (No. inhibition) \\
\hline Kurrat & $2(<50 \% \downarrow$ intensity $)$ & 0 (No. inhibition) & 0 (No. inhibition) & 0 (No. inhibition) & 0 (No. inhibition) \\
\hline
\end{tabular}

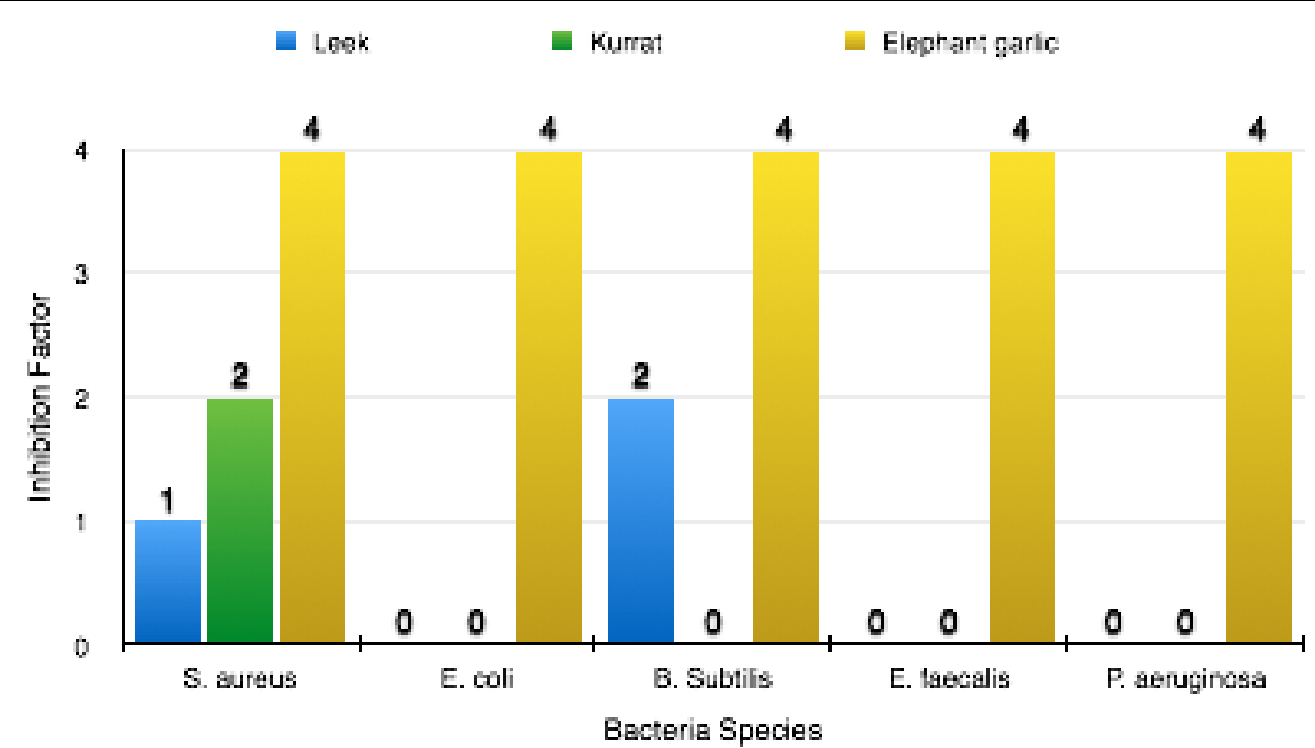

Fig. 1 Antibacterial activity of Wild Leek (A. ampeloprasum var. porrum), Kurrat (A. ampeloprasum var. kurrat) and Elephant Garlic (A. ampeloprasum var. ampeloprasum) extractsagainst the five bacteria Bacillus subtilis, Pseudomonas aeruginosa, Escherichia coli, Enterococcus faecalis, and Staphylococcus aureus expressed in inhibition factor coefficients. 


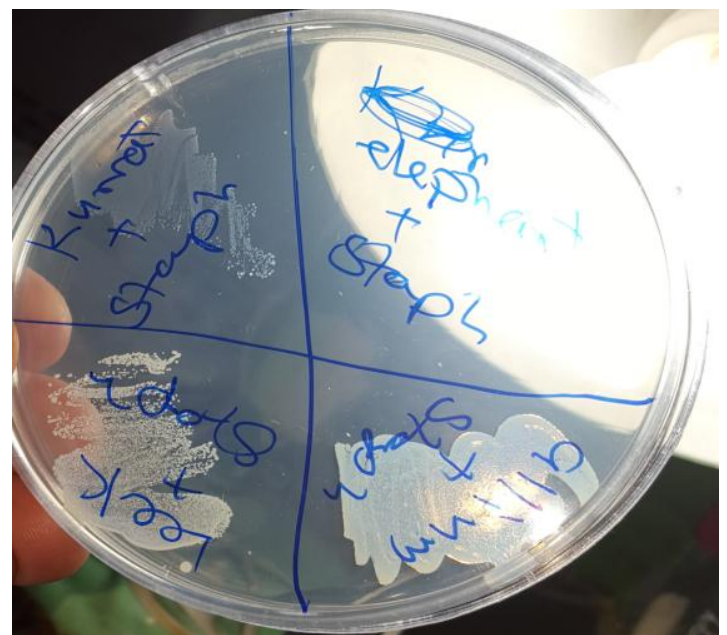

Fig. 2 Step two of the antibacterial activities test of Wild Leek (A. ampeloprasum var. porrum), Kurrat (A. ampeloprasum var. kurrat) and Elephant Garlic (A. ampeloprasum var. ampeloprasum) against Staphylococcus aureus. Higher transparency correlates with a higher inhibition.

proven to possess, their unpleasant odor, taste and chemical instability (i.e. to temperature) limits the scope of their use as a potential replacement for commercially available antibiotics. Certain allergies to these herbal extracts also limit their possible use as disinfectant agents.

\section{Conclusion}

According to our results, we have concluded that the water extracts of the mentioned broadleaf leeks possessed factors that inhibited the growth of a wide range of bacteria. We have also observed that a $50 \%$ decrease in the concentration of our most effective extract (elephant garlic) lowered the inhibition zone of all the tested bacteria by almost $50 \%$. However, the inhibitory strengths were entirely dependent on the type of the leeks. Previous studies suggest that the antibacterial activity of these herbs is due to the presence of sulfur-containing compounds in their chemical composition. [7] While cysteine sulfoxides are known to be the chemical agents of Allium that possess antibacterial qualities, exact composition of these agents in leeks are yet to be determined. Effective inhibition of elephant garlic against the wide range of tested bacteria with medium to high resistance show that this herbal extract could prove effective in use as an antimicrobial agent upon further investigations and studies.

We propose further studies to elucidate the effect of elephant garlic extract on multi-drug resistant bacteria such as Methicillin-resistant Staphylococcus aureus (MRSA) that are present in hospital settings where infections are common and cause life-threatening diseases.

\section{Acknowledgments}

Authors would like to thank TIECO laboratories for providing the rotary vacuum distillation unit used in this study. Authors would also like to thank the Shiraz Shahriar Hospital pathobiology laboratories for providing the appropriate bacterial strains, equipment and guidelines.

Special thanks are owed to Mr. Daniel Ajerman, science department chair of Léman Manhattan Preparatory School, for his generous guidance throughout this research.

\section{References}

[1] Pankaj, S., Balqees, Al-T., Najat, Al-N., and Rahma, Al-M. 2012. "Effect of Temperature on Antibiotic Properties of Garlic (Allium sativum L.) and Ginger (Zingiber officinale Rosc.)." African Journal of Biotechnology 11 (95): 16192-5.

[2] Cdc. Gov. 2011. "Data and Statistics." HAI, CDC'. N. P. Accessed September 2015. http://www.cdc.gov/HAI/surveillance/.

[3] Okeke, I. N., Lamikanra, A., and Edelman, R. 1999. "Socioeconomic and Behavioral Factors Leading to Acquired Bacterial Resistance to Antibiotics in Developing Countries." Emerging Infectious Diseases 5 (1): 18-27.

[4] U.S. National Library of Medicine. 2015. Bacterial Infections: Medline Plus. U.S. National Library of Medicine, N. D.

[5] Griffiths G., Trueman L., Crowther T., Thomas B., and Smith B. 2002. "Onions-A Global Benefit to Health." Phytotherapy Research 16 (7): 603-15.

[6] Elnima, E. I., Ahmed S. A., Mekkawi, A. G., and Mossa, J. S. 1983. "The Antimicrobial Activity of Garlic and Onion Extracts." Die Pharmazie 38 (11): 747-8. 
[7] Benkeblia, N. 2004. "Antimicrobial Activity of Essential Oil Extracts of Various Onions (Allium cepa) and Garlic (Allium sativum)." LWT-Food Science and Technology 37: 263-8.

[8] Kim, J., Marshall, M. R., and Wei, C. 1995. “Antibacterial Activityof Some Essential Oil Components against Five Foodborne Pathogens." Journal of Agriculture and Food Chemistry 43: 2839-45.

[9] Deans, S. G., and Ritchie, G. 1987. "Antibacterial Properties of Plant Essential Oils.” International Journal of Food Microbiology 5 (2): 165-80.

[10] Saxena, A., Tripathi, R. M. and Singh, R. P. 2010. "Biological Synthesis of Silver Nanoparticles by Using Onion (Allium cepa) Extract and Their Antibacterial Activity." Dig. J. Nanomater Bios. 5 (2): 427-32.

[11] Hughes, B. G., and Larry D. L. 1991. "Antimicrobial Effects of Allium sativum L. (Garlic), Allium
Ampeloprasum L. (Elephant Garlic), and Allium cepa L. (Onion), Garlic Compounds and Commercial Garlic Supplement Products." Phytotherapy Research 5 (4): 154-8.

[12] Bakri, I. M., and Douglas, C. W. I. 2005. "Inhibitory Effect of Garlic Extract on Oral Bacteria." Archives of Oral Biology 50 (7): 645-51.

[13] Durairaj, S., Sangeetha S., and Lakshmanaperumalsamy, P. 2009. "In Vitro Antibacterial Activity and Stability of Garlic Extract at Different $\mathrm{pH}$ and Temperature." Electronic Journal of Biology 5 (1): 5-10.

[14] Lanzotti, V. 2006. "The Analysis of Onion and Garlic." Journal of Chromatography A. 1112 (1-2): 3-22.

[15] Santas, J., María Pilar, A., and Rosa, C. 2010. "Antimicrobial and Antioxidant Activity of Crude Onion (Allium cepa, L.) Extracts." International Journal of Food Science and Technology 45 (2): 403-9. 